\title{
Microencapsulation of anthocyanin-rich black soybean coat extract by spray drying using maltodextrin, gum Arabic and skimmed milk powder
}

\author{
Ana Kaluševića,b, Steva Levića ${ }^{a}$ Bojan Čalija ${ }^{c}$, Milena Pantića ${ }^{a}$ Miona Belovićd, Vladimir Pavlovića, \\ Branko Bugarski ${ }^{e}$, Jela Milićc, Slađana Žilić ${ }^{\prime}$ and Viktor Nedovića \\ ${ }^{a}$ Department of Food Technology and Biochemistry, Faculty of Agriculture, University of Belgrade, Belgrade, Serbia; ${ }^{b}$ Institute of Meat \\ Hygiene and Technology, Belgrade, Serbia; 'Department of Pharmaceutical Technology and Cosmetology, Faculty of Pharmacy, \\ University of Belgrade, Belgrade, Serbia; ${ }^{d}$ Institute of Food Technology, University of Novi Sad, Novi Sad, Serbia; ${ }^{\text {eDepartment of }}$ \\ Chemical Engineering, Faculty of Technology and Metallurgy, University of Belgrade, Belgrade, Serbia; 'Department of Food \\ Technology and Biochemistry, Maize Research Institute, Belgrade, Serbia
}

\begin{abstract}
Black soybean coat is insufficiently valorised food production waste rich in anthocyanins. The goal of the study was to examine physicochemical properties of spray dried extract of black soybean coat in regard to carrier materials: maltodextrin, gum Arabic, and skimmed milk powder. Maltodextrin and gum Arabic-based microparticles were spherical and non-porous while skimmed milk powder-based were irregularly shaped. Low water activity of microparticles (0.31-0.33), good powders characteristics, high solubility (80.3-94.3\%) and encapsulation yields (63.7-77.0\%) were determined. All microparticles exhibited significant antioxidant capacity (243-386 $\mu \mathrm{molTE} / \mathrm{g})$, good colour stability after three months of storage and antimicrobial activity. High content of total anthocyanins, with cyanidin-3-glucoside as predominant, were achieved. In vitro release of anthocyanins from microparticles was sustained, particularly from gum Arabic-based. These findings suggest that proposed simple eco-friendly extraction and microencapsulation procedures could serve as valuable tools for valorisation and conversion of black soybean coat into highly functional and stable food colourant.
\end{abstract}

\section{ARTICLE HISTORY}

Received 10 February 2017

Revised 27 June 2017

Accepted 10 July 2017

\section{KEYWORDS}

Black soybean coat; anthocyanin-rich extract; spray drying; microencapsulation; microparticles; colourant

\section{Introduction}

Valorisation of food processing waste and recovery of valuable bioactive compounds has attracted great attention in the recent years. Black soybean coats is one of the insufficiently used food waste with high antioxidant potential (Žilić et al., 2013) and health-promoting effects (Kim et al., 2008). Industrial and domestic processing of the soybean into various products for human and animal consumption has being increased. The production of the most of these products includes decoating and separating coats from the beans. Therefore, coat remains as a byproduct in production of soybean oil, soybean meal (a protein supplement in poultry, hog and cattle feed), soy protein isolate, soyflour, soy-milk, tofu, soy-akara, soymoi-moi, dadawa, soy-ogi etc. (Agulanna et al., 2011). A main difference between yellow (standard) and black soybeans is in their anthocyanin and proanthocyanidin contents concentrated in the epidermal layer of the seed coat (Žilić et al., 2013). Anthocyanins have been investigated due to their ability to reduce the risk of different diseases like atherosclerosis, cancer, diabetes, ischemia, obesity and neurodegenerative disorders (Kim et al., 2008, 2012). Anthocyanins as the most abundant group of pigments have found their application in food, pharmaceutics and cosmetics. From a commercial standpoint an attractive and stable colour is one of the most important sensorial properties of food products. Hence, anthocyanins could be used as natural colourants to improve both food colour and sensorial quality. However, one of the main problems related to processing and storage of anthocyanins is their sensitivity to various factors such as temperature, light, oxygen, $\mathrm{pH}$, the presence of solvents and metal ions. Additionally, colour of food containing petunidin or malvidin aglycones is more stable than that of those rich in cyanidin, pelargonidin or delphinidin (Von Elbe and Schwartz, 1996). The acylation of anthocyanins with organic acids improves colour stability (Li et al., 2011). Recently, there are increasing demands in food industry for colourants of plant origin that have both

CONTACT Viktor Nedovic $\otimes$ vnedovic@agrif.bg.ac.rs $@$ Department of Food Technology and Biochemistry, Faculty of Agriculture, University of Belgrade, Belgrade, Serbia

(C) 2017 Informa UK Limited, trading as Taylor \& Francis Group 
colouring and health-benefit properties. Contrary to the artificial additives, natural colourants such as anthocyanins have been investigated due to their ability to reduce the risk of different diseases like atherosclerosis, cancer, diabetes, ischemia, obesity and neurodegenerative disorders (Kim et al., 2008, 2012). In general, one of the most suitable preservation methods for anthocyanin-rich juices and extracts is the spray drying process. Hence, the encapsulation could be an effective solution for anthocyanins protection and stability improvement, as well as their incorporation into foods.

Among the numerous techniques, spray drying was found to be promising tool for protection of bioactive compounds such as anthocyanins from food processing waste via encapsulation (de Souza et al., 2015; Díaz et al., 2015; Laokuldilok and Kanha 2015, 2017).

The main advantages of spray drying over the other encapsulation techniques are simplicity, continuity, cost- and time-effectiveness, availability and applicability, even for the drying of sensitive compounds since the atomisation of the liquid mixture lasts extremely shortly. However, spray drying do not provides uniform conditions into drying chamber and easy control of particle size, as well as drying of highly viscous solutions (Nedović et al., 2013; Belščak-Cvitanović et al., 2015).

Maltodextrin (MD) and gum Arabic (GA) have been frequently used as carrier materials for microencapsulation of different juices, infusions extracts and various functional byproducts via spray drying (Cano-Chauca et al., 2005; Belščak-Cvitanović et al., 2015; Díaz et al., 2015; de Souza et al., 2015; Santiago-Adame et al., 2015; Laokuldilok and Kanha, 2015, 2017; Daza et al., 2016). Skimmed milk powder (SMP) provides very high yield of encapsulates, nonstick properties, high encapsulation efficiency, and it is very convenient for application as a cheap and easily accessible material (Bylaitë et al., 2001; Shamaei et al., 2017). Besides, as a source of protein, lactose, vitamins and minerals, this material provides additional nutritional value (Jing and Gusti, 2005). However, it has been rarely reported about SMP as a carrier for anthocyanin-rich materials.

To the best of our knowledge, this is the first report on the microencapsulation of black soybean coat extract (SCE). Therefore, the objective of this study was to investigate possibility of utilisation of black soybean coat, as a byproduct and source of bioactives, via microencapsulation; and to investigate the influence of different encapsulating materials of natural origin on functionality of the obtained microparticles as potential food colourants.

\section{Materials and methods}

\section{Material}

The Black Tokyo, soybean genotype (with black seed coat) used in this study was grown at the location of the Maize Research Institute Zemun Polje (MRIZP). The whole black soybeans were separated into seed coats and dehulled beans. The separated seed coats were finely ground on a Perten 120 lab mill (Perten, Sweden) to fine powder (particle size $<500 \mu \mathrm{m}$ ) and stored at $-70^{\circ} \mathrm{C}$.

Maltodextrin with dextrose equivalent $(D E=16-19.9)$ produced by Cargill was kindly provided from Palco (Serbia). GA was purchased from Himedia (India), as well as Müeller Hinton Broth/Agar. SMP was generously donated by dairy Subotička mlekara (Serbia). Tryptone Soy Broth/Agar was purchased from Oxoid (Hampshire, UK). All other chemicals used for the experimental procedures were of analytical or HPLC grade and used as such without further purification.

\section{Microencapsulation process}

\section{Preparation of black soybean coat extract}

Milled black coat was extracted with ethanol $70 \%(\mathrm{v} / \mathrm{v})$ acidified with citric acid, $1 \%(\mathrm{~m} / \mathrm{v})$ during the period of $2 \mathrm{~h}$. The samples were extracted in the ratio $1: 40(\mathrm{~m} / \mathrm{v})$ at ambient temperature by shaking (150 rev/min) with the application of ultrasound $(40 \mathrm{kHz}, 10 \mathrm{~min} / \mathrm{h})$. Afterward, the ethanol was removed using a vacuum evaporator at $40^{\circ} \mathrm{C}$. Extracts were diluted by distilled water to adjust previous volume.

\section{Preparation of feed mixtures for spray drying}

The feed mixtures were prepared by mixing the SCE $(100 \mathrm{ml})$ with the carriers $(7.5 \mathrm{~g})$. The homogenisation of the mixtures was carried out at ambient temperature for approximately $15 \mathrm{~min}$.

\section{Encapsulation by spray drying}

Encapsulation was carried out using a Büchi mini B290 spray dryer (Büchi Labortechnik AG, Switzerland) equipped with the standard $0.7 \mathrm{~mm}$ diameter nozzle. The inlet and outlet temperatures were $140^{\circ} \mathrm{C}$ and $70 \pm 2{ }^{\circ} \mathrm{C}$, respectively. The air flow rate, rate of liquid feed, atomisation pressure were $600 \mathrm{~L} / \mathrm{h}, 8 \mathrm{ml} / \mathrm{min}$, and 0.55 bar, respectively.

\section{Physical and chemical characterization of spray dried microparticles}

\section{Microparticles morphology and size distribution}

Scanning electronic microscopy (SEM) analysis was performed using a JEOL JSM 6390LV microscope (Japan). 
The samples were attached to stubs using a two-sided adhesive tape, and sputter coated with gold $(50 \mathrm{~nm})$ for $100 \mathrm{~s}$ at $30 \mathrm{~mA}$ (Sputter Coater BAL-TEC SCD 005). The SEM was operated at $15 \mathrm{kV}$ with a magnification of 2000. The microparticle size was analysed from SEM micrographs using ImageJ analysis software. The particle diameter for each formulation was calculated as the average value of the diameter of 100 spray dried microparticles. The span was chosen to describe the particle size distribution (PSD) width expressed by:

$$
\left(d_{(\mathrm{v}, 90)}-d_{(\mathrm{v}, 10)}\right) / d_{(\mathrm{v}, 50)}
$$

where $d_{(v, 90)}, d_{(v, 50)}$, and $d_{(v, 10)}$ are diameters at 90 , 50 and $10 \%$ of cumulative volume, respectively. In other words $\left(d_{(v, 90)}-d_{(v, 10)}\right)$ is the range of the data and $d_{(v, 50)}$ is the median diameter.

\section{Flow properties of microparticles}

Bulk and tapped density of the samples were determined following the method described in The European Pharmacopeia (Ph. Eur 8.0, 2014; 2.9.34). Tapped volume was determined by mechanical tapping of a graduated glass cylinder placed on a STAV 2003 volumeter (Gemini B.V. Apeldoorn, Netherlands).

Microparticles compressibility was estimated by calculating and comparing values of compressibility index (Cl) and Hausner ratio (HR). $\mathrm{Cl}$ and HR depend on a difference between bulk volume and final tapped volume of the microparticles, and according to $\mathrm{Ph}$. Eur. 8.0 (2014), can be used as a measure of the propensity of a material to be compressed.

\section{Solubility, moisture content and water activity of microparticles}

The microparticles $(0.5 \mathrm{~g})$ were dissolved in $50 \mathrm{ml}$ of distilled water and continuously stirred for $30 \mathrm{~min}$ at $150 \mathrm{rpm}$ followed by centrifugation at $5000 \mathrm{rpm}$, for $5 \mathrm{~min}$. The supernatant was dried in the drying oven at $105^{\circ} \mathrm{C}$ until constant weight. The dried weight of soluble solid was measured and used to calculate the solubility as a percentage.

The moisture content of the spray dried microparticles was determined by the oven drying method. Samples of the microparticles with predefined mass were placed in a drying oven heated at $105^{\circ} \mathrm{C}$ and weighed until constant mass. The product moisture content was determined from the weight loss. Water activity $\left(a_{\mathrm{w}}\right)$ of microparticles was determined by using a water activity metre (Testo 650 Water Activity System; Cole-Parmer, Vernon Hills, IL, USA).
Fourier transform infrared spectroscopy (FTIR) and differential scanning calorimetry (DSC) analysis

ATR-FTIR analysis of samples was performed with an IRAffinity-1 FTIR spectrophotometer (Schimadzu, Japan). The range was from 4000 to $600 \mathrm{~cm}^{-1}$, while the resolution was $4 \mathrm{~cm}^{-1}$.

The differential scanning calorimetry (DSC) experiments were performed using a DSC 1 instrument (Mettler-Toledo, Switzerland). Analyses were performed from 25 and $300^{\circ} \mathrm{C}$, at a heating rate of $10^{\circ} \mathrm{C} / \mathrm{min}$ under constant nitrogen purge of $50 \mathrm{ml} / \mathrm{min}$. The empty sealed pan was used as a reference.

\section{Colour measurements}

The colour of samples was directly measured with Chroma Meter CR-400 (Konica Minolta, Japan), using attachment for liquid (CM-A98) and granular materials (CR-A50). CIE L*a*b* parameters: L* (lightness), a* (redness/greenness), $b^{*}$ (yellowness/blueness), $C^{*}$ (chroma), $\mathrm{h}^{\circ}$ (hue angle), and dominant wavelength were read using a D65 light source. The total colour change after 90 days of storage at $25^{\circ} \mathrm{C}$ was calculated according to Díaz et al. (2015).

\section{The total phenolic content}

The total phenolic content was determined by the Folin-Ciocalteu assay as described by Singleton and Rossi (1965) and expressed as microgram of gallic acid equivalent (GAE) per gram of microparticles ( $\mu \mathrm{g}$ $\mathrm{GAE} / \mathrm{g}$ ).

\section{The total monomeric anthocyanin content}

The total monomeric anthocyanin content was determined by a pH differential method (Lee et al., 2005). The concentration was expressed as microgram of cyanidin-3-glucoside equivalents per gram of microparticles ( $\mu \mathrm{g}$ CGE/g).

\section{Content of individual anthocyanins}

Anthocyanins for chromatographic analyses were extracted from microparticles dissolved in the water using methanol acidified with $1 \mathrm{M} \mathrm{HCl}(85: 15, \mathrm{v} / \mathrm{v})$. The HPLC analyses were carried out with an HPLC-DAD system (Thermo Scientific Ultimate 3000). Chromatograms were obtained at $530 \mathrm{~nm}$ after injection of $10 \mu \mathrm{L}$ of sample. Separation was performed on a Thermo Scientific Hypersil GOLD aQ C18 column $(150 \mathrm{~mm} \times$ $4.6 \mathrm{~mm}$, particle size $3 \mu \mathrm{m}$ ) using a linear gradient elution programme with a mobile phase containing solvent $A$ (formic acid/ $\mathrm{H}_{2} \mathrm{O}, 1: 99, \mathrm{v} / \mathrm{v}$ ), and solvent $B$ 
(formic acid/acetonitrile, 1:99, v/v) at a flow rate of $0.7 \mathrm{ml} / \mathrm{min}$ and column oven temperature of $30^{\circ} \mathrm{C}$. The following gradient was established: linear gradient elution from $10 \% \mathrm{~B}$ to $30 \% \mathrm{~B}, 0-30 \mathrm{~min}$; linear gradient elution from $30 \%$ B to $100 \%$ B, 30-35 min; isocratic elution of $100 \%$ B , 35-38 min; linear gradient elution from $100 \% B$ to $10 \% \mathrm{~B}, 38-40 \mathrm{~min}$; isocratic elution of $10 \%$ B, $40-45$ min. Pure anthocyanin compounds such as cyanidin 3-glucoside (Cy-3-Glu), pelargonidin 3-glucoside (Pg-3-Glu), cyanidin 3,5-diglucoside (Cy-3,5diGlu), delfinidin 3-glucoside (De-3-Glu), petunidin 3-glucoside (Pt-3-Glu) and malvidin 3-glucoside (Mal-3Glu) were used as standards. Data were processed using the Thermo Scientific Dionex Chromeleon 7.2. Chromatographic software. The results were expressed as microgram per gram of microparticles $(\mu \mathrm{g} / \mathrm{g})$.

\section{Yield of microencapsulation process}

The process yield was calculated from equation shown below, as the ratio of the total dry weight of the microparticles obtained $\left(W_{2}\right)$ and the dry weight of the material in its own feed mixture $\left(W_{1}\right)$. The process yield was expressed as a percentage (\%).

$$
\text { Yield }(\%)=\left(W_{2} / W_{1}\right) \times 100
$$

\section{In vitro release of anthocyanins from microparticles}

The release of anthocyanins from microparticles was performed using a CE7 Smart flow-through cell dissolution apparatus (Sotax, Westborough, MA, USA) in the open loop configuration under a constant medium flow rate at $1 \mathrm{ml} / \mathrm{min}$ for $2 \mathrm{~h}$ at $37^{\circ} \mathrm{C}$. The release studies were performed in distilled water and in the media simulating $\mathrm{pH}$ conditions in different parts of gastrointestinal tract: $0.1 \mathrm{M} \mathrm{HCl}$ solution (simulated gastric fluid (SGF), pH 1.2) and USP phosphate buffers (simulated small intestinal fluid (SIF), $\mathrm{pH} 6.8$, and simulated colonic fluid (SCF), pH 7.4) (Čalija et al., 2013). At scheduled time intervals, samples were withdrawn, filtered and assayed spectrophotometrically by described $\mathrm{pH}$ differential method. The average percentage of released anthocyanins was plotted versus time.

\section{Analysis of the total antioxidant capacity}

Total antioxidant capacity was determined by QUENCHER method described by Serpen et al. (2008) using ABTS (2,2-azino-bis/3-ethil-benothiazoline-6-sulfonic acid) reagent. The total antioxidant capacity was expressed as Trolox equivalent antioxidant capacity
(TEAC) in micromol of Trolox equivalent per gram of microparticles ( $\mu \mathrm{mol} \mathrm{TE} / \mathrm{g}$ ).

\section{Antimicrobial assay}

For antibacterial activity assay, Gram-positive (Bacillus spizizeni ATCC 6633, Staphylococcus aureus ATCC 25923 and Listeria monocytogenes ATCC 19111) and Gram-negative strains (Pseudomonas aeruginosa ATCC 27853, Escherichia coli 0157:H7 ATCC 35150, Salmonella enteritidis ATCC 13076 and Yersinia enterocolitica ATCC 27729) were used. The cultivation medium for L. monocytogenes and E. coli O157:H7 was Tryptone Soy Broth/Agar and for others it was Müeller Hinton Broth/Agar. Overnight culture grown aerobically for $20 \mathrm{~h}$ at $37^{\circ} \mathrm{C}$ was diluted to obtain a density of $10^{5}-10^{6} \mathrm{CFU} / \mathrm{mL}$ (Duvnjak et al., 2016).

The minimal inhibitory concentrations (MIC) of microparticles were determined by broth microdilution method. All samples were evaluated at the concentrations ranging from $4.7 \mathrm{mg}$ to $300 \mathrm{mg} / \mathrm{mL}$. As an indicator of cell growth resazurin sodium salt $(6.75 \mathrm{mg} / \mathrm{mL})$ was used. The MIC and minimum microbicidal concentration $(\mathrm{MBC})$ were defined according to method described by Duvnjak et al. (2016).

\section{Statistical analysis}

The analytical data were reported as mean \pm standard deviation of the minimum three independent repetitions per analysis. The experimental data were subjected to a one-way analysis of variance (ANOVA) and Tuckey's test was used to detect difference $(p \leq 0.05)$ between the mean values. Statistical analyses were performed with the statistical programme STATISTICA 12 (Data Analysis Software System; Stat-Soft, Inc., St. Tulsa, OK, USA).

\section{Results and discussion}

\section{Morphology and physical properties of microparticles}

As shown in Figure 1, microparticles were poly-dispersed in size, regardless of the carrier material, with average diameters below $10 \mu \mathrm{m}$.

Scanning electronic microscopy analysis has shown well-formed spherical, non-porous and smooth surfaced MD-based microparticles with wide diameter distribution $(3.6 \pm 2.6 \mu \mathrm{m}$, Figure $1(\mathrm{a}))$.

The acceptable, but not ideal spherical shape of SCE/GA microparticles with average diameter of 

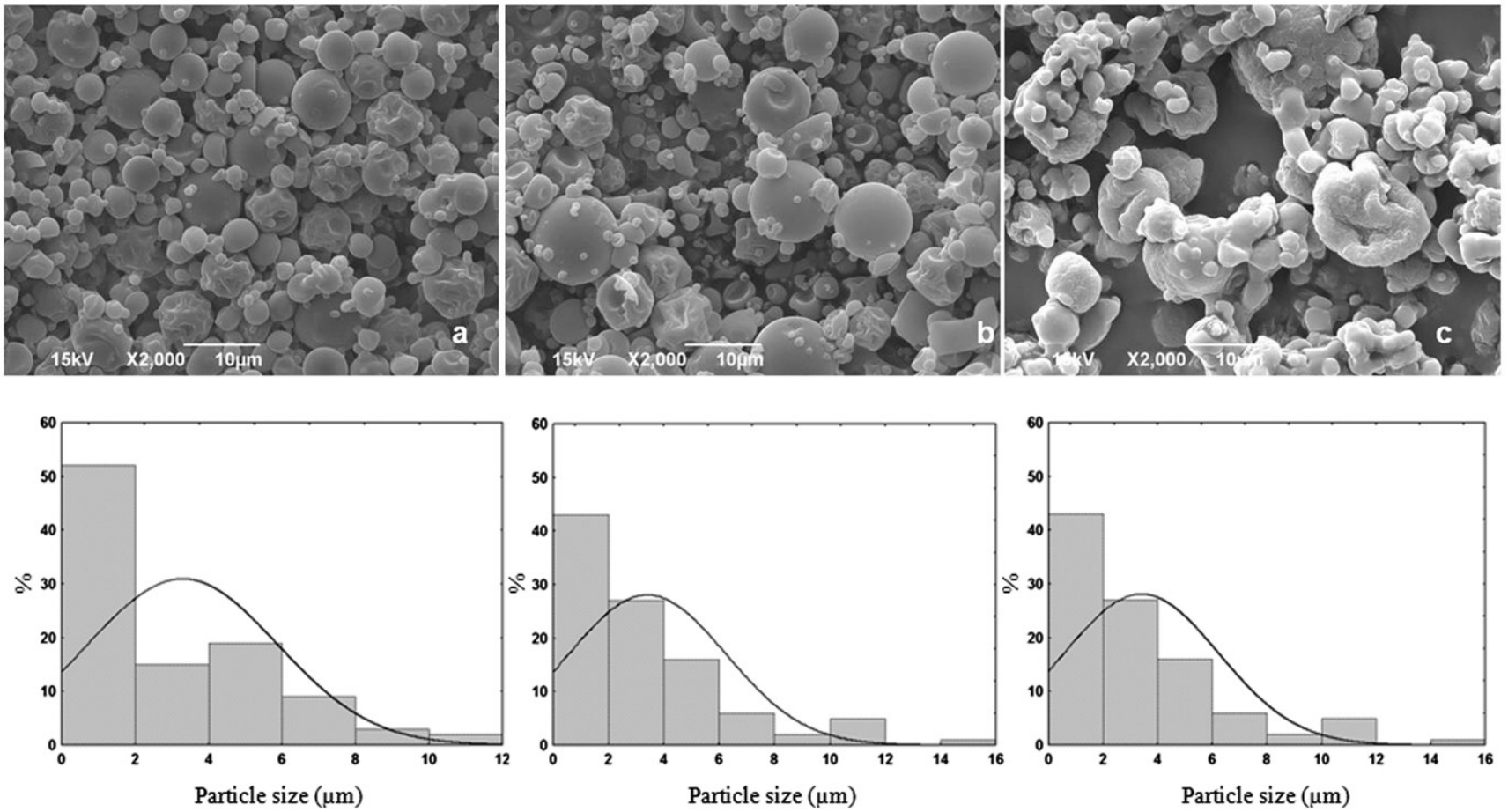

Figure 1. SEM micrographs of soybean coat extract microparticles with maltodextrin (MD) (a), gum Arabic (GA) (b), and skimmed milk powder (SMP) (c) with corresponding size distribution histograms.

Table 1. Physical properties of soybean coat extract microparticles with maltodextrin, gum Arabic and skimmed milk powder.

\begin{tabular}{|c|c|c|c|c|c|c|c|c|c|c|}
\hline Sample & $\mathrm{BD}(\mathrm{g} / \mathrm{mL})$ & $\mathrm{TD}(\mathrm{g} / \mathrm{mL})$ & $\mathrm{Cl}(\%)$ & $\mathrm{HR}$ & $a_{\mathrm{w}}$ & MC (\%) & S (\%) & $d(\mu \mathrm{m})$ & PSD width $(\mu \mathrm{m})$ & $Y(\%)$ \\
\hline$\overline{S C E} / \mathrm{MD}$ & $0.23 \pm 0.04^{\mathrm{a}}$ & $0.26 \pm 0.00^{\mathrm{a}}$ & $25.0 \pm 1.0^{\mathrm{a}}$ & $1.33 \pm 0.03^{\mathrm{a}}$ & $0.33 \pm 0.01^{\mathrm{a}}$ & $5.2 \pm 0.6^{\mathrm{a}}$ & $94.3 \pm 0.4^{\mathrm{a}}$ & $3.6 \pm 2.6^{\mathrm{a}}$ & $3.23 \pm 0.08^{\mathrm{a}}$ & $71.2 \pm 3.4^{\mathrm{a}}$ \\
\hline SCE/GA & 0.20 & $0.27=$ & 29.0 & $1.41 \pm$ & $0.31 \pm 0.00^{b}$ & $6.8 \pm 0.7^{\mathrm{a}}$ & $89.3 \pm 1.2^{b}$ & $2.8^{\mathrm{a}}$ & $.18^{\mathrm{b}}$ & $63.7 \pm 9.5^{\mathrm{a}}$ \\
\hline SCE/SMP & $0.18 \pm 0.02^{\mathrm{a}}$ & $0.22 \pm 0.02^{\mathrm{a}}$ & $18.8 \pm 2.0^{c}$ & $1.23 \pm 0.02^{c}$ & $0.32 \pm 0.00^{\mathrm{ab}}$ & $6.7 \pm 0.7^{\mathrm{a}}$ & $80.3 \pm 0.7^{c}$ & $2.8 \pm 1.6^{\mathrm{a}}$ & $1.57 \pm 0.06^{c}$ & $77.0 \pm 2.0^{\mathrm{a}}$ \\
\hline
\end{tabular}

SCE/MD: soybean coat extract/maltodextrin; SCE/GA: soybean coat extract/gum Arabic; SCE/SMP: soybean coat extract/skimmed milk powder; BD: bulk density; TD: tapped density; $\mathrm{Cl}$ : compressibility index; HR: Hausner ratio; $a_{\mathrm{w}}$ : water activity; MC: moisture content; S: solubility; $d$ : mean microparticles diameter; PSD: particle size distribution (SPAN), Y: yield. Values are shown as means \pm SD $(n=3)$. Different letters within columns indicate a significant difference at $* p<0.05$.

$3.4 \pm 2.8 \mu \mathrm{m}$ could be ascribed to the gum characteristics (Figure 1(b)).

The SMP-based microparticles sized $2.8 \pm 1.6 \mu \mathrm{m}$ have had collapsed forms (Figure 1(c)), which are typical for spray dried particles, due to rapid drying. Same forms of microparticles were noticed after spray drying of walnut oil with SMP at $140^{\circ} \mathrm{C}$ (Shamaei et al., 2017), and could be ascribed to the presence of lactose and casein in the carrier material. Such problems for spray dried SMP powders could be attributed to the effect of conditions of atomisation and drying on casein (Bylaitë et al., 2001). In this study, the PSD width for microparticles was calculated as span values (Table 1). The range of the span values was between $1.57 \pm 0.06$ and $4.90 \pm 0.18$. The PSD is an important parameter in food powders since it directly affects other physical properties of the product. The correlations between the PSD values and the $\mathrm{Cl}$ and HR values of microparticles were extremely high $(R=0.97$ in both cases).
The comparison of MD, GA and SMP-based microparticles bulk and tapped density, $\mathrm{Cl}$ and $\mathrm{HR}$, water activity, solubility and yield are given in Table 1 .

Solubility, as the ability of powders to form solution in the water is an important physicochemical property that influences powder's functional characteristics in food systems. High solubility of all samples has been found in following order: SCE/SMP $<\mathrm{SCE} / \mathrm{GA}<\mathrm{SCE} /$ MD. Similarly, the solubility over $90 \%$ has been reported for fruit extracts spray dried with MD and GA (Cano-Chauca et al., 2005; Daza et al., 2016). The solubility values for MD- and GA-based microparticles were expected, since those materials are widely used as carrier in spray drying processes due to theirs high solubility. However, the results for SMP-based microparticles proved that this material is also a good carrier. As previously reported, solubility values increase with addition of carrier (Daza et al., 2016).

Water activity is an important factor controlling processability, handling properties and stability of 
spray dried microparticles and powders, in general. The water activity of obtained microparticles was low ( $\sim 0.3)$ suggesting that they could be stored for prolonged period of time, without significant risk of microbiological spoilage. Beside microbiological stability, stickiness and caking are frequent problems in handling of powders especially those containing amorphous carbohydrates, such as lactose in SMP. Also, the nonenzymatic browning reaction is substantially accelerated by an increase in water activity following crystallisation of amorphous lactose in dairy powders. For mentioned problems most of authors consider $a_{\mathrm{w}}$ around 0.4 as critical (Roos, 2002; Maltini et al., 2003).

The moisture contents of microparticles are shown in Table 1. Low moisture contents such here presented could prevent the agglomeration of microparticles avoiding the caking phenomena, and consequently decrease retention of actives, dispersion and/or powder flowability (Daza et al., 2016). However, in the most applications of food processing and storage, the choice of $a_{\mathrm{w}}$ values as the reference parameter rather than moisture content is based on a numerous important effects $\left(a_{\mathrm{w}}\right.$ is related to growth of microorganisms, chemical, enzymatic, and physical degradation reactions, as well as easier and non-destructive measurements).

According to $\mathrm{Cl}$ and HR values, obtained microparticles could be defined as powders with fair, passable and poor flow characteristics for SCE/SMP, SCE/MD, and SCE/GA microparticles, respectively.

The results of MD-based microparticles yield are in high correlation with yields of spray dried anthocyanin-rich extract with MD reported by Laokuldilok and Kanha (2015). GA-based microparticles showed similar results to those reported by Fazaeli et al. (2012) about spray dried black mulberry juice with same carrier material. The highest yield was achieved for SMPbased microparticles. Similar results have been reported in the study comparing milk protein-based microparticles with other carrier materials (BelščakCvitanović et al., 2015). Regarding powder properties and microparticles yield, SMP was found as promising carrier material for anthocyanins microencapsulation.

\section{FTIR and DSC analysis}

The chemical properties and interactions between microparticles compounds were analysed using FTIR spectroscopy (Figure 2). The bands at $1716 \mathrm{~cm}^{-1}$, $1604 \mathrm{~cm}^{-1}$ and $1517 \mathrm{~cm}^{-1}$, as well as bands in the spectral regions $1400-1000 \mathrm{~cm}^{-1}$ and $700-1000 \mathrm{~cm}^{-1}$ in the spectrum of SCE (Figure 2(a)) could be

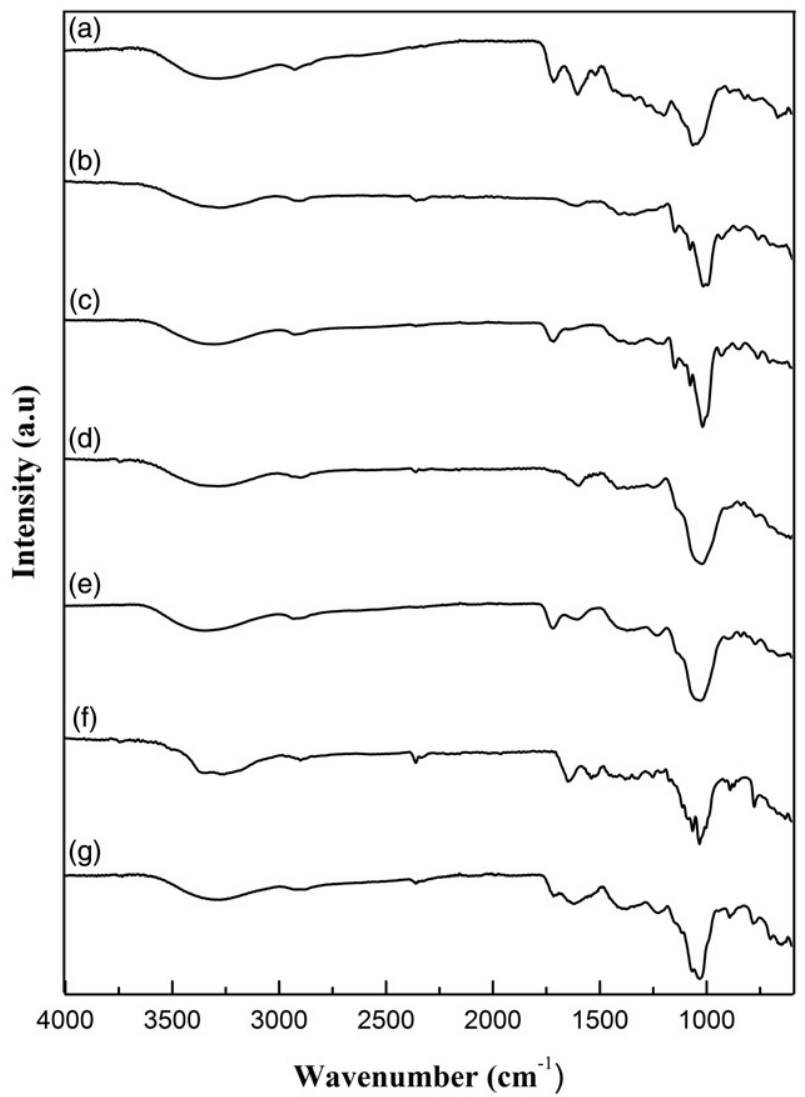

Figure 2. FTIR spectra of soybean coat extract (SCE) (a), carrier materials: maltodextrin (b), gum Arabic (d), skimmed milk powder (f), and microencapsulated SCE in the carriers: SCE/MD (c), SCE/GA (e), SCE/SMP (g).

associated with extracted polyphenols described by Arancibia-Avila et al. (2012) and Pereira et al. (2015). The other prominent bands are at $\sim 3300 \mathrm{~cm}^{-1}$ $\left(\mathrm{OH}\right.$ groups) and $2927 \mathrm{~cm}^{-1}$ (C-H stretching band).

The FTIR spectra of the carriers (Figure 2) showed several characteristic bands related to structure and chemical groups present in these materials. All three carrier materials exhibited broad and strong bands around $3300 \mathrm{~cm}^{-1}$ due to $\mathrm{OH}$ vibrations, as well as bands at $\sim 2900 \mathrm{~cm}^{-1}$ from C-H bond stretching vibration (Espinosa-Andrews et al., 2010; Nicolaou et al., 2010; de Souza et al., 2015), while the bands in the spectra of MD and GA are characteristic for carbohydrates (around $1000 \mathrm{~cm}^{-1}$ ), which are in good agreement with literature data (Espinosa-Andrews et al., 2010; de Souza et al., 2015). In the FTIR spectrum of SMP (Figure 2(f)) the bands associated with amide I $\left(\sim 1650 \mathrm{~cm}^{-1}\right)$ and amide II $\left(\sim 1540 \mathrm{~cm}^{-1}\right)$ (due to protein presence), as well as lactose (around $1000 \mathrm{~cm}^{-1}$ ) were also reported earlier (Nicolaou et al., 2010).

The FTIR spectra of SCE/MD and SCE/GA microparticles (Figure 2(c,e)) showed bands originating from the carrier materials and SCE compounds. The only 

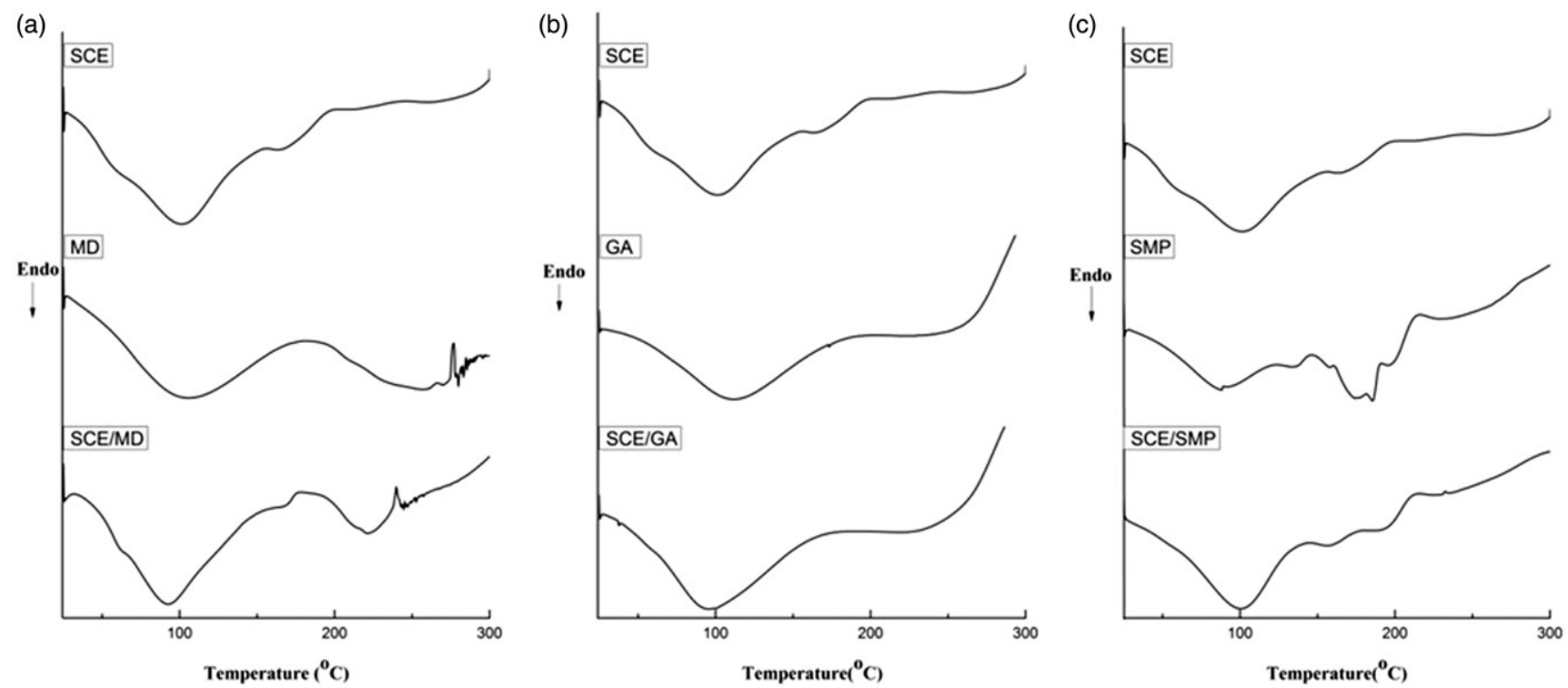

Figure 3. DSC thermograms of soybean coat extract (SCE), maltodextrin (MD), gum Arabic (GA), skimmed milk powder (SMP) and the corresponding spray dried microparticles (SCE/MD, SCE/GA, SCE/SMP).

significant differences could be observed in the spectrum of SCE/SMP (Figure 2(g)), where instead of the bands from amide I and amide II of milk proteins, the new broad band at $1620 \mathrm{~cm}^{-1}$ could be observed, indicating possible interactions between extracted polyphenols and milk proteins. The interactions between milk proteins and polyphenols have been studied recently (Hasni et al., 2011). These chemical interactions could provide some additional information about stability of polyphenols encapsulated into microparticles (see below).

Differential scanning calorimetry study of SCE, carriers (MD, GA, SMP) and microparticles was performed to investigate possible interactions between individual components and thermal stability of the microparticles (Figure 3).

Non-encapsulated SCE showed a broad endothermic event with peak around $100^{\circ} \mathrm{C}$, most probably due to water loss and almost absence of significant exothermic effects up to $300^{\circ} \mathrm{C}$ (Figure 3), indicating satisfactory thermal stability of extracted compounds. As can be seen in Figure 3, SCE maintained thermal stability upon microencapsulation, showing no significant exothermic event below $250^{\circ} \mathrm{C}$.

All the three carrier materials are characterised with broad endothermic peaks around $100^{\circ} \mathrm{C}$. While MD and GA exhibited endothermic maxima at $106^{\circ} \mathrm{C}$ and $112^{\circ} \mathrm{C}$, respectively, due to water loss (Sousdaleff et al., 2013), the endothermic peak for SMP occurred at lower temperature $\left(88^{\circ} \mathrm{C}\right)$. Differences in position and intensities of these endothermic peaks could be ascribed to different water content and sample affinity for water molecules. Further temperature increase led to the second endothermic event in MD and GA thermograms, followed by exothermic effects above $250^{\circ} \mathrm{C}$ due to melting and subsequent degradation of the two polymers, respectively. Above $250^{\circ} \mathrm{C}$, the thermograms of $\mathrm{MD}$ and GA showed exothermic processes connected to melting and subsequent degradation of these compounds (Klein et al., 2015). The SMP also exhibited satisfactory thermal stability, a necessary property for carriers exposed to high process temperatures.

The endothermic peaks of MD and GA-based microparticles were insignificantly shifted to the lower temperatures (Figure $3(a, b)$ ). Contrary to those two samples, slight shift of this peak toward higher temperatures suggests faintly higher thermal stability of SMP-based microparticles. Due to complex chemical structure of SMP, it is not easy to detect and identify all thermal processes during analysis of SMP-based microparticles. The main reason could be thermal transformations of milk proteins during spray drying that could lead to changes in the proteins structure and their thermal properties (Pugliese et al., 2016). Nevertheless, all of these potential proteins structural changes had no effect on SMP as a carrier, which provided microparticles with satisfactory physical properties, as previously discussed. The FTIR and DSC analyses showed that obtained microparticles are chemically and thermally stable systems for encapsulation of soybean coat polyphenols. No strong interactions between carriers and SCE that could undermine the encapsulation efficiency and stability of polyphenols were observed. Moreover, improvement of functional and technological properties of microparticles 
Table 2. Colour parameters (CIELab) of the soybean coat extract, carrier materials and the spray dried microparticles.

\begin{tabular}{|c|c|c|c|c|c|c|}
\hline Sample & $L^{*}$ & $a^{*}$ & $b^{*}$ & $C^{*}$ & $\mathrm{~h}$ & DWL \\
\hline$\overline{\mathrm{SCE}}$ & $21.70 \pm 0.01^{\mathrm{a}}$ & $25.63 \pm 0.01^{\mathrm{a}}$ & $7.19 \pm 0.01^{\mathrm{a}}$ & $26.62 \pm 0.05^{\mathrm{a}}$ & $15.67 \pm 0.16^{\mathrm{a}}$ & $665.8 \pm 6.7^{\mathrm{a}, \mathrm{e}}$ \\
\hline MD & $95.14 \pm 0.11^{b}$ & $-1.19 \pm 0.01^{b}$ & $1.33 \pm 0.01^{b}$ & $1.78 \pm 0.01^{b}$ & $131.91 \pm 0.13^{b}$ & $560.5 \pm 0.1^{b, d}$ \\
\hline $\mathrm{SCE} / \mathrm{MD}_{0}$ & $64.42 \pm 1.08^{\mathrm{c}}$ & $37.87 \pm 0.18^{\mathrm{c}}$ & $5.53 \pm 0.21^{c}$ & $38.27 \pm 0.21^{\mathrm{c}}$ & $8.30 \pm 0.27^{c}$ & $494.7 \pm 0.1^{c}$ \\
\hline SCE/MD ${ }_{90}$ & $64.86 \pm 0.59^{c}$ & $36.19 \pm 0.39^{c, d}$ & $5.20 \pm 0.23^{c}$ & $36.57 \pm 0.42^{c}$ & $8.18 \pm 0.25^{c}$ & $494.7 \pm 0.0^{c}$ \\
\hline $\mathrm{GA}$ & $85.38 \pm 0.10^{\mathrm{e}}$ & $1.19 \pm 0.01^{\mathrm{e}}$ & $9.88 \pm 0.04^{d}$ & $9.95 \pm 0.04^{\mathrm{d}}$ & $83.16 \pm 0.02^{d}$ & $578.0 \pm 0.0^{\mathrm{b}, \mathrm{d}, \mathrm{f}}$ \\
\hline $\mathrm{SCE} / \mathrm{GA}_{0}$ & $68.83 \pm 0.01^{d}$ & $28.82 \pm 0.03^{f}$ & $6.93 \pm 0.02^{\mathrm{a}}$ & $29.64 \pm 0.03^{\mathrm{e}}$ & $13.53 \pm 0.05^{\mathrm{e}}$ & $611.5 \pm 58.8^{d, e, f}$ \\
\hline $\mathrm{SCE} / \mathrm{GA}_{90}$ & $68.34 \pm 0.00^{d}$ & $28.78 \pm 0.04^{f}$ & $7.19 \pm 0.01^{\mathrm{a}}$ & $29.67 \pm 0.03^{\mathrm{e}}$ & $14.03 \pm 0.06^{\mathrm{e}}$ & $654.9 \pm 1.2^{\mathrm{a}, \mathrm{e}, \mathrm{f}}$ \\
\hline SMP & $94.87 \pm 0.01^{\mathrm{b}}$ & $-3.09 \pm 0.01^{\mathrm{b}}$ & $10.78 \pm 0.01^{\mathrm{e}}$ & $11.22 \pm 0.01^{d}$ & $106.02 \pm 0.02^{f}$ & $571.5 \pm 0.0^{\mathrm{d}}$ \\
\hline $\mathrm{SCE} / \mathrm{SMP}_{0}$ & $64.71 \pm 0.02^{c}$ & $34.15 \pm 0.03^{\mathrm{d}, \mathrm{g}}$ & $2.30 \pm 0.02^{f}$ & $34.23 \pm 0.03^{f}$ & $3.80 \pm 0.03^{\mathrm{g}}$ & $496.1 \pm 0.0^{c}$ \\
\hline SCE/SMP & $67.25 \pm 0.01^{c, d}$ & $33.49 \pm 0.03^{g}$ & $1.98 \pm 0.02^{b, f}$ & $33.55 \pm 0.03^{f}$ & $3.38 \pm 0.03^{g}$ & $496.3 \pm 0.0^{c}$ \\
\hline
\end{tabular}

SCE: soybean coat extract; MD: maltodextrin; SCE/MD: soybean coat extract/maltodextrin; GA: gum Arabic; SCE/GA: soybean coat extract/gum Arabic; SMP: skimmed milk powder; SCE/SMP: soybean coat extract/skimmed milk powder; 0: before storage (0 days); 90 : after storage (90 days); L*: lightness; a*: redness/greenness; b*: yellowness/blueness; $C^{*}$ : chroma; h: hue angle; DWL: Dominant wave length. Values are shown as means \pm SD $(n=3)$. Different letters within columns indicate a significant difference at ${ }^{*} p<0.05$.

(e.g. the smallest diameter, the highest anthocyanin content, the highest yield, etc.) could be related to the possible chemical interactions between milk proteins and SCE compounds.

\section{Colour measurements}

As the most important characteristics of the majority of food products, the colour plays a very significant role in the acceptability since it is first judged by consumers of food products.

Hence, the preservation of anthocyanins colour properties during storage is critical for potential application of these compounds as natural colourants. The results of chromatic parameters measurements are presented in Table 2.

The initial extract had the lowest value for $L^{*}$, which was expected for the liquid sample. Based on the parameters $a^{*}, b^{*}$ and hue angle, it can be concluded that colours of the carrier materials were varied from purely white to light yellow, while SCE microparticles were light red (originating from SCE) with certain proportion of yellowness. The colour of microparticles significantly differs from those of carriers and SCE (Table 2). The hue angle (3.80-13.53) of all the microparticles exhibited generally the red colour, with values lower than for SCE. After microencapsulation all $\mathrm{L}^{*}, \mathrm{a}^{*}$, and $\mathrm{C}^{*}$ values of microparticles were significantly higher in comparison with extract (SCE) and it is conducted with their different forms (liquid and solid). However, the values for all colour parameters among microparticles based on same carrier were no statistically different $\left({ }^{*} p<0.05\right)$ after the storage period.

Among all microparticles SCE/MD had the lowest value for lightness $\left(L^{*}\right)$ and the highest values for $a^{*}$ and $C^{*}$, which indicates that this sample was the darkest with the highest proportion of red colour. Similar results for $C^{*}$ and $h^{\circ}$ values were reported for spray dried black glutinous rice anthocyanins microparticled with various maltodextrins with explanation that the increase of temperature and DE of maltodextrin cause a darker colour (Laokuldilok and Kanha, 2017). The initial and the final values ( $t=0$ days and $t=90$ days) of the microparticles show that the GA as carrier gave higher lightness values compared with the MD and SMP. Table 2 shows that storage period have not affected the colour change at the ambient storage temperature. However, the yellowness increased in all sample and storage condition (Table 2). This implied that the colour of powders has become darker in comparison with control or nonencapsulated samples and the powders tend to become brownish because of the increase in yellowness. It was found that during storage the changes of $a^{*}$ and $b^{*}$ of all sample were in the range of approximately one unit differences. This indicated only minor changes of the microparticles shade and colour and the minor, but still detected changes of redness might be caused by the degradation of anthocyanins during storage (Idham et al., 2012). The total colour change was the highest for SCE/SMP microparticles (2.64), and the smallest for SCE/GA microparticles (0.56). Since the colour is one the most important critical quality attributes for food products, all the microparticles were tested on colour stability. All samples showed high colour stability which is preferable property of microparticles and could be the basis for their potential applications as food additives (i.e. natural colourants).

\section{Total polyphenol, total and individual anthocyanin contents of microparticles}

According to results presented in Table 3, the microparticles showed a variety of the total phenolic and anthocyanins contents.

All investigated samples were high in concentration of anthocyanins with Cy-3-Glu was predominantly present among other detected anthocyanins (Pg-3-Glu 
Table 3. The content of total phenolic content, total anthocyanin content and individual anthocyanin content of spray dried microparticles.

\begin{tabular}{lccc}
\hline & SCE/MD & SCE/GA & SCE/SMP \\
\hline TPC $(\mu \mathrm{g} \mathrm{GAE} / \mathrm{g})$ & $7521.6 \pm 170.0$ & $9660.0 \pm 320.1$ & $6225.0 \pm 195.5$ \\
TAC $(\mu \mathrm{g} \mathrm{CGE} / \mathrm{g})$ & $1780.7 \pm 40.0$ & $1591.0 \pm 63.5$ & $1923.0 \pm 39.3$ \\
Cy-3-Glu $(\mu \mathrm{g} / \mathrm{g})$ & $1620.8 \pm 19.5$ & $1355.0 \pm 25.6$ & $1708.0 \pm 32.8$ \\
Pg-3-Glu $(\mu \mathrm{g} / \mathrm{g})$ & $122.9 \pm 11.5$ & $188.8 \pm 10.0$ & $150.5 \pm 18.3$ \\
De-3-Glu $(\mu \mathrm{g} / \mathrm{g})$ & $10.9 \pm 2.0$ & nd $^{\mathrm{a}}$ & $11.5 \pm 2.0$ \\
\hline
\end{tabular}

SCE/MD: soybean coat extract/maltodextrin; SCE/GA: soybean coat extract/gum Arabic, SCE/SMP: soybean coat extract/skimmed milk powder; TPC: total phenolic content; TAC: total anthocyanin content; Cy-3-Glu: cyanidin-3-0-glucoside; Pg-3-Glu: Pelargonidin-3-O-glucoside; De-3-Glu: Delphinidin-3-0-glucoside. Data are expressed as mean \pm SD $(n=3)$; $\mathrm{nd}^{\mathrm{a}}$ : not detected.

and De-3-Glu), and accounted for over $90 \%$ of the total.

Gum Arabic-based showed the highest TPC and the lowest TAC. These results could be related to stabilising and emulsifying effects of GA on microencapsulation of some phenolic compounds, but also to dissolution of this carrier in different $\mathrm{pH}$ mediums used for analysis of TPC and TAC. MD shows easier dissolution in broad $\mathrm{pH}$ range of solvents, so there is a good correlation in case of microparticles based on this material.

In general, $\beta$-casein as a component of SMP forms stronger complexes with polyphenols than $\alpha$-casein, due to more hydrophobic nature. Since that, polyphenol-casein interactions are more hydrophobic than hydrophilic (Hasni et al., 2011). The casein structural changes could be a main factor in the effect of SMP on the TPC, TAC and antioxidant activity of SMP-based microparticles. SMP-based microparticles showed the highest contents of anthocyanins, possibly due to very efficient extraction by acidified solvents. Namely, the interactions between anthocyanins and protein involve hydrophobic effects and hydrogen bonds which are generally reversible and strongly dependent on $\mathrm{pH}$ (Jing and Gusti, 2005). One group of researchers recently reported that the casein proteins interacted with anthocyanins, such as malvidin-3-glucoside from grape, by hydrogen bonding and hydrophobic reaction forming complexes and effectively protecting the anthocyanins from degradation, improving their thermal, oxidation and photo stability (He et al., 2016).

\section{In vitro release of anthocyanins from microparticles}

The dissolution/release profiles of total anthocyanin content (TAC) from the spray-dried powders in distilled water, SGF, SIF, and SCF are given in Figure 4. The dissolution tests were performed in the gastric, small intestine and colonic fluids to simulate $\mathrm{pH}$ conditions in gastrointestinal tract. MD-based microparticles showed release profile similar to those reported previously for MD-based carriers at pH 6 (Santiago-Adame et al., 2015). In SGF (Figure 4(b)) SCE/SMP microparticles showed the rapid release of anthocyanins similarly to SCE/MD microparticles. The rapid release of TAC from MD-based microparticles could be ascribed to the high water solubility of MD. In contrast, GAbased microparticles exhibited slow release with less than $50 \%$ of TAC released for $2 \mathrm{~h}$ of experiment. It could be attributed to the gum properties since gums as the carriers provide the most favourable dissolution/release pattern (Belščak-Cvitanović et al., 2015).

Release rates of the anthocyanins from spray dried powders in SIF (Figure 4(c)) in the first $60 \mathrm{~min}$ were quite various (36-78\%), with the slowest release from SCE/SMP microparticles during second hour.

Since GA enabled a prolonged (i.e. the slowest) release of TAC in the water, similarly as in SGF and SCF (Figure 4(d)), it can be concluded that GA as the carrier provides the most suitable release pattern from the microparticles. Additionally, the lowest concentration of anthocyanins in the GA-based microparticles (Table 3) could be explained with a prolonged release and an incomplete extraction by the acidified solvents.

\section{Total antioxidant capacity of microparticles}

Antioxidant capacity assay was performed on the investigated carrier materials and microparticles (Figure 5). The carrier materials showed various antioxidant capacity $(0.63-75.45 \mu \mathrm{mol} \mathrm{TE} / \mathrm{g})$. MD as carrier had no effect on the antioxidant potential of SCE/MD, which is in agreement with results of Gil et al. (2014), where MD also showed the lowest TEAC value among other carriers used for spray drying.

The highest antioxidant capacity among carriers was observed in SMP due to well-known antioxidant capacity of milk and caseins (Sharma et al., 2008). Results for GA and SMP could be ascribed to the antioxidant capacity of malanoidins, formed by Maillard reaction from sugars and proteins (as components in carriers) at high temperatures during spray drying process (Wang et al., 2011).

The total antioxidant capacities of the MD-, GA- and SMP-based microparticles were 388.6, 5.6, and 4.0 times higher in comparison with corresponding carriers, respectively. This indicates that even the carrier materials must be analysed in order to establish the exact contribution of each microparticles constitutes in the total antioxidant capacity values.

In MD-based microparticles antioxidant capacity could be ascribed to anthocyanins and other phenols 

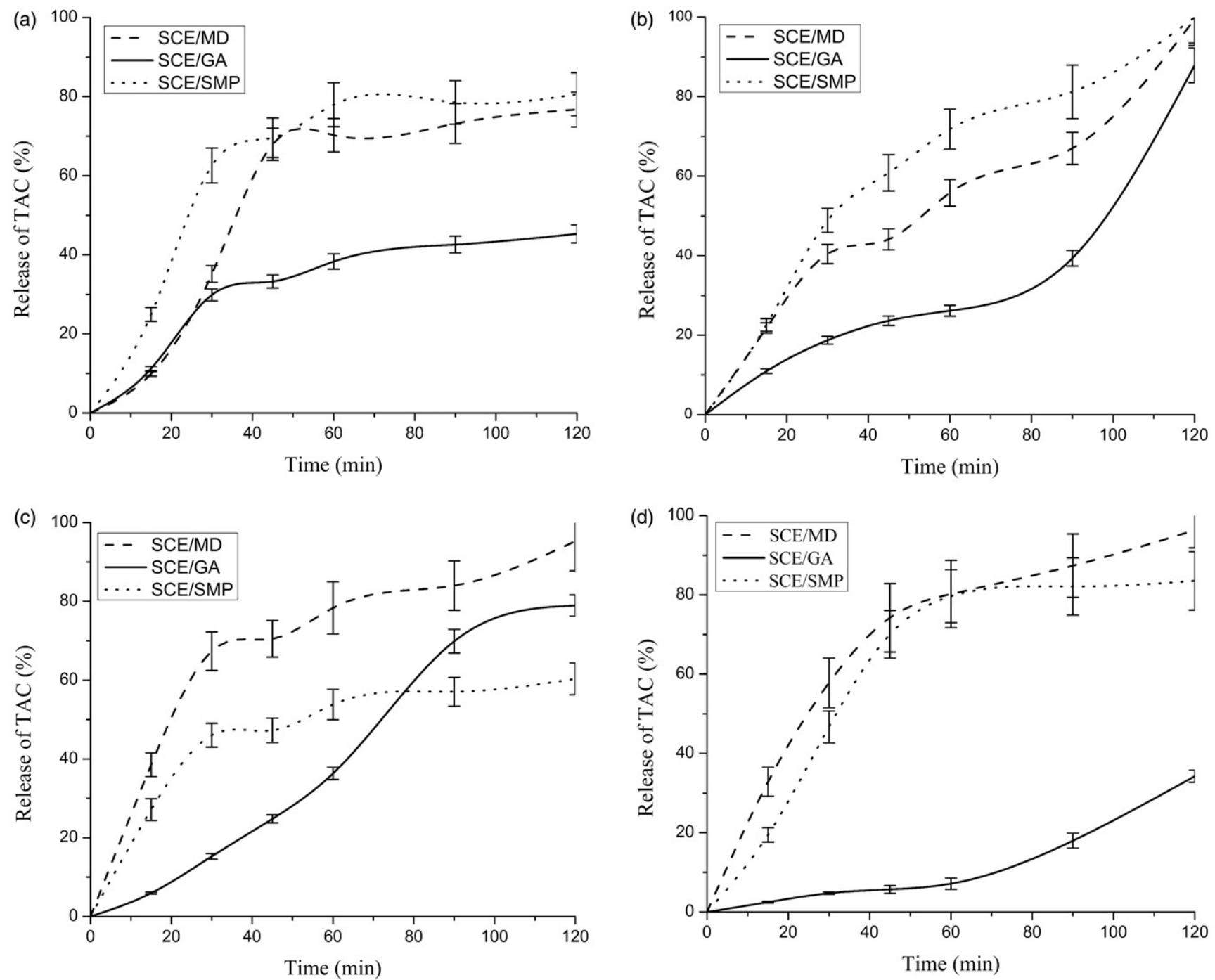

Figure 4. Anthocyanins release profiles from microparticles of spray dried soybean coat extract in: distilled water (a), simulated gastric fluid (SGF) (b), simulated intestinal fluid (SIF) (c), and simulated colonic fluid (SCF) (d).

from SCE. Generally, the higher inlet temperature causes thermal degradation of anthocyanins, and thus the lower radical scavenging activity (Laokuldilok and Kanha, 2017). SCE/GA has shown the highest antioxidant capacity among all the investigated microparticles, due to presence of both, phenolic compounds from SCE, and melanoidins (Žilić et al., 2016).

In case of this sample and SMP-based microparticles, the significant influence was ascribed to antioxidant potential of carriers. Some studies revealed that addition of milk increases and stabilise the tea antioxidant capacity (Sharma et al., 2008).

\section{Antimicrobial activity}

Minimal inhibitory concentrations and minimum microbicidal concentration assays demonstrated that analysed samples exhibited different inhibitory effects.
Table 4 shows the antimicrobial activity of the spray dried SCE against seven bacteria. All the samples showed antimicrobial activity against $B$. spizizeni, in the same minimal inhibition concentrations $(4.7 \mathrm{mg} /$ $\mathrm{mL}$ ). In case of SCE/GA and SCE/SMP, twice higher concentrations inhibited $L$. monocytogenes and $Y$. enterocolitica growth. These concentrations were about 15 to 30 times lower than those that inhibited S. enteritidis and $P$. aeruginosa. These results, as well as absence of inhibition, like in case of $E$. coli could be attributed to the presence of the second lipid bilayer system in the membrane of Gram-negative bacteria which obstructs the penetration of antimicrobial agents.

However, while in some cases low concentrations are needed to achieve a bactericidal effect, for some bacteria concentration higher than $300 \mathrm{mg} / \mathrm{mL}$ should be applied. Only SCE/GA microparticles showed effect 


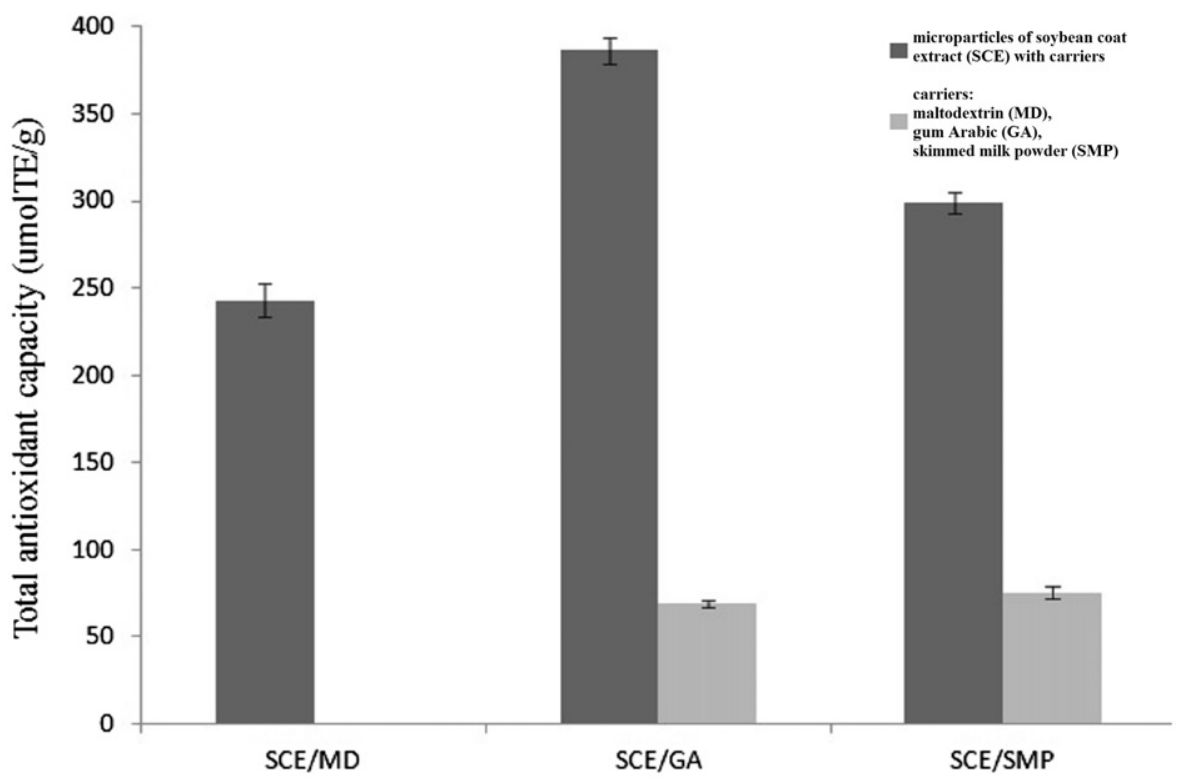

Figure 5. Total antioxidant capacity of plane microparticles of maltodextrin (MD), gum Arabic (GA) and skimmed milk powder (SMP) and microencapsulated soybean coat extract with maltodextrin (SCE/MD), gum Arabic (SCE/GA) and skimmed milk powder (SCE/SMP).

Table 4. Minimum inhibitory concentration $(\mathrm{mg} / \mathrm{mL})$ and minimum bactericidal concentration $(\mathrm{mg} / \mathrm{mL})$ of soybean coat extract microparticles produced with maltodextrin, gum Arabic, skimmed milk powder.

\begin{tabular}{|c|c|c|c|c|c|c|}
\hline \multirow{2}{*}{$\begin{array}{l}\text { Sample } \\
\text { Microorganism }\end{array}$} & \multicolumn{2}{|c|}{ SCE/MD } & \multicolumn{2}{|c|}{ SCE/GA } & \multicolumn{2}{|c|}{ SCE/SMP } \\
\hline & $\mathrm{MIC}(\mathrm{mg} / \mathrm{mL})$ & $\mathrm{MBC}(\mathrm{mg} / \mathrm{mL})$ & $\mathrm{MIC}(\mathrm{mg} / \mathrm{mL})$ & $\mathrm{MBC}(\mathrm{mg} / \mathrm{mL})$ & $\mathrm{MIC}(\mathrm{mg} / \mathrm{mL})$ & $\mathrm{MBC}(\mathrm{mg} / \mathrm{mL})$ \\
\hline B. spizizeni ATCC 6633 & $4.7 \pm 0.0$ & $9.4 \pm 0.0$ & $4.7 \pm 0.0$ & $9.4 \pm 0.0$ & $4.7 \pm 0.0$ & $9.4 \pm 0.0$ \\
\hline L. monocytogenes ATCC 19111 & $n d^{a}$ & nd & $9.4 \pm 0.0$ & $18.8 \pm 0.0$ & $9.4 \pm 0.0$ & $18.8 \pm 0.0$ \\
\hline S. aureus ATCC 25923 & nd & nd & $150.0 \pm 0.0$ & $300.0 \pm 0.0$ & $300.0 \pm 0.0$ & nd \\
\hline Y. enterocolitica ATCC 27729 & nd & nd & $9.4 \pm 0.0$ & $18.8 \pm 0.0$ & $9.4 \pm 0.0$ & $18.8 \pm 0.0$ \\
\hline E. coli 0157:H7 ATCC 35150 & nd & nd & $37.5 \pm 0.0$ & $75.0 \pm 0.0$ & nd & nd \\
\hline S. enteritidis ATCC 13076 & $300.0 \pm 0.0$ & nd & $300.0 \pm 0.0$ & nd & $300.0 \pm 0.0$ & nd \\
\hline P. aeruginosa ATCC 27853 & $150.0 \pm 0.0$ & $300.0 \pm 0.0$ & $150.0 \pm 0.0$ & $300.0 \pm 0.0$ & $300.0 \pm 0.0$ & nd \\
\hline
\end{tabular}

SCE/MD: soybean coat extract/maltodextrin; SCE/GA: soybean coat extract/gum Arabic; SCE/SMP: soybean coat extract/skimmed milk powder; MIC: Minimum inhibitory concentration; MBC: minimum bactericidal concentration. Data are expressed as mean \pm SD $(n=3)$, nd ${ }^{\text {a }}$ not detected.

against all used bacteria which is in agreement with the obtained values of total antioxidant capacities.

\section{Conclusions}

The results confirmed spray drying at $140^{\circ} \mathrm{C}$ with $\mathrm{MD}$, GA and SMP as an efficient technique to produce anthocyanin-rich powders with good physical powder properties, thermal, chemical, microbial and colour stability. The obtained dissolution/release profiles indicated prolonged release of anthocyanins in different $\mathrm{pH}$ conditions, achieved primarily using GA. MD-based microparticles showed the fastest and complete release in water, which can be even suitable for some applications. All the microparticles showed strong bactericidal effect against $B$. spizizeni, while the strongest inhibition effect, in general, has showed GA-based microparticles. This sample had the highest antioxidant potential, also.
The process described in this study could be applied in the food industry. Also, and the materials used as raw material and carriers, are relatively cheap and readily available, making the described process inexpensive. The use of these microparticles in many food products in order to have natural colourants with their bioactive potentials, as oppose to artificial ones, could represent new opportunities for utilisation of such extracts and microencapsulation.

All investigated microparticles exhibited significantly high colour stability during 90 days long storage period at ambient temperature, which is preferable property and could represent the basis for their potential applications as food additives (i.e. natural colourants).

\section{Acknowledgements}

This work is supported by the projects of Ministry of Education and Science and Technological Development, 
Serbia, $N^{\circ} 46010$ and $N^{\circ} 31069$. Authors are grateful to $\mathrm{Dr}$ Vesna Perić and Dr Mirjana Srebrić (Maize Research Institute, Breeding Department, Belgrade-Zemun, Serbia) for providing black soybean genotype used in this study.

\section{Disclosure statement}

No potential conflict of interest was reported by the authors.

\section{References}

Agulanna CN, Oriaku EC, Edeh JC. Improving productivity in soya-bean processing through the design and fabrication of double action decoating and separation machine. J Emerg Trends Eng Appl Sci, 2011;2(3):487-93.

Arancibia-Avila P, Namiesnik J, Toledo F, Werner E, MartinezAyala AL, Rocha-Guzmán NE, Alberto Gallegos-Infante JA, Gorinstein $S$. The influence of different time durations of thermal processing on berries quality. Food Control, 2012;26(2):587-93.

Belščak-Cvitanović A, Lević $S$, Kalušević A, Špoljarić I, Dorđević V, Komes D, Mršić G, Nedović V. Efficiency assessment of natural biopolymers as encapsulants of green tea (Camellia sinensis L.) bioactive compounds by spray drying. Food Bioprocess Technol, 2015;8(12): 2444-60.

Bylaitë E, Venskutonis PR, Mapdpierienë R. Properties of caraway (Carum carvi L.) essential oil encapsulated into milk protein-based matrices. Eur Food Res Technol, 2001;212(6):661-70.

Cano-Chauca M, Stringheta PC, Ramos AM, Cal-Vidal J. Effect of the carriers on the microstructure of mango powder obtained by spray drying and its functional characterization. Innov Food Sci Emerg Technol, 2005;6(4):420-8.

Čalija B, Cekić N, Savić S, Daniels R, Marković B, Milić J. PHsensitive microparticles for oral drug delivery based on alginate/oligochitosan/Eudragit ${ }^{\circledR}$ L100-55 "sandwich" polyelectrolyte complex. Colloids Surf B: Biointerf, 2013;110: 395-402.

Daza LD, Fujita A, Fávaro-Trindade CS, Rodrigues-Ract JN, Granato D, Genovese MI. Effect of spray drying conditions on the physical properties of Cagaita (Eugenia dysenterica DC.) fruit extracts. Food Bioproducts Process, 2016;97: 20-9.

de Souza BV, Thomazini M, de Carvalho Balieiro CJ, FávaroTrindade SC. Effect of spray drying on the physicochemical properties and color stability of the powdered pigment obtained from vinification byproducts ofthe Bordo grape (Vitis labrusca). Food Bioprod Process, 2015;93:39-50.

Díaz DI, Beristain Cl, Azuara E, Luna G, Jimenez M. Effect of wall material on the antioxidant activity and physicochemical properties of Rubus fruticosus juice microcapsules. J Microencapsulat, 2015;32(3):247-54.

Duvnjak D, Pantić M, Pavlović V, Nedović V, Lević S, Matijašević D, Sknepnek A, Nikšić M. Advances in batch culture fermented Coriolus versicolor medicinal mushroom for the production of antibacterial compounds. Innov Food Sci Emerg Technol, 2016;34:1-8.
European Pharmacopeia, 2014 (8th ed., 2.9.34). Strasbourg: European Directorate for the Quality of Medicines \& HealthCare of the Council of Europe (EDQM).

Espinosa-Andrews H, Sandoval-Castilla O, Vázquez-Torres $\mathrm{H}$, Vernon-Carter EJ, Lobato-Calleros C. Determination of the gum Arabic-chitosan interactions by Fourier Transform Infrared Spectroscopy and characterization of the microstructure and rheological features of their coacervates. Carbohydr Polym, 2010;79(3):541-6.

Fazaeli M, Emam-Djomeh Z, Ashtari AK, Omid M. Effect of spray drying conditions and feed composition on the physical properties of black mulberry juice powder. Food Bioproducts Process, 2012;90(4):667-75.

Gil M, Restrepo A, Millán L, Alzate L, Rojano B. Microencapsulation of banana passion fruit (Passiflora tripartita var. mollissima): A new alternative as a natural additive as antioxidant. Food Nutr Sci, 2014;5:671-82.

Hasni I, Bourassa P, Hamdani S, Samson G, Carpentier R, Tajmir-Riahi HA. Interaction of milk $\alpha$ - and $\beta$-caseins with tea polyphenols. Food Chem, 2011;126(2):630-9.

He Z, Xu M, Zeng M, Qin F, Chen J. Interactions of milk $\alpha$-and $\beta$-casein with malvidin-3-O-glucoside and their effects on the stability of grape skin anthocyanin extracts. Food Chem, 2016;199:314-22.

Idham Z, Muhamad II, Sarmidi MR. Degradation kinetics and color stability of spray-dried encapsulated anthocyanins from Hibiscus sabdariffa L. J Food Process Eng, 2012;35(4):522-42.

Jing $P$, Giusti MM. Characterization of anthocyanin-rich waste from purple corncobs (Zea mays L.) and its application to color milk. J Agric Food Chem, 2005;53(22):8775-81.

Kim HK, Kim JN, Han SN, Nam JH, Na HN, Ha TJ. Black soybean anthocyanins inhibit adipocyte differentiation in 3T3L1 cells. Nutr Res, 2012;32(10):770-7.

Kim JM, Kim JS, Yoo H, Choung MG, Sung MK. Effects of black soybean [Glycine max (L.) Merr.] seed coats and it anthocyanidins on colonic inflammation and cell proliferation in vitro and in vivo. J Agric Food Chem, 2008;56(18): 8427-33.

Klein T, Longhini R, Bruschi ML, de Mello JCP. Microparticles containing guaraná extract obtained by spray-drying technique: Development and characterization. Rev Bras Farmacognosia, 2015;25(3):292-300.

Laokuldilok T, Kanha N. Effects of processing conditions on powder properties of black glutinous rice (Oryza sativa L.) bran anthocyanins produced by spray drying and freeze drying. LWT Food Sci Technol, 2015;64(1):405-11.

Laokuldilok T, Kanha N. Microencapsulation of black glutinous rice anthocyanins using maltodextrins produced from broken rice fraction as wall material by spray drying and freeze drying. J Food Process Preserv, 2017;41(1):e12877. doi: 10.1111/jfpp.12877.

Li J, Walker CE, Faubion JM. Acidulant and oven type affect total anthocyanin content of blue corn cookies. J Sci Food Agric, 2011;91(1):38-43.

Lee J, Durst RW, Wrolstad RE. Determination of total monomeric anthocyanin pigment content of fruit juices, beverages, natural colorants, and wines by the $\mathrm{pH}$ differential method: Collaborative study. J AOAC Int, 2005;88(5): 1269-78. 
Maltini E, Torreggiani D, Venir E, Bertolo G. Water activity and the preservation of plant foods. Food Chem, 2003;82(1):79-86.

Nedović V, Kalušević A, Manojlović V, Petrović T, Bugarski B. 2013. Encapsulation Systems in the Food industry. In: Yanniotis S, Taoukis P, Stoforos NG, Karathanos VT, eds. Advances in food process engineering research and applications, food engineering series. US: Springer, pp. 229-253.

Nicolaou N, Xu Y, Goodacre R. Fourier transform infrared spectroscopy and multivariate analysis for the detection and quantification of different milk species. J Dairy Sci, 2010;93(12):5651-60.

Pereira VA Jr, de Arruda INQ, Stefani R. Active chitosan/PVA films with anthocyanins from Brassica oleraceae (red cabbage) as time-temperature indicators for application in intelligent food packaging. Food Hydrocoll, 2015;43: 180-8.

Pugliese A, Paciulli M, Chiavaro E, Mucchetti G. Characterization of commercial dried milk and some of its derivatives by differential scanning calorimetry. J Therm Anal Calorim, 2016;123(3):2583-90.

Roos $\mathrm{YH}$. Importance of glass transition and water activity to spray drying and stability of dairy powders. Le Lait, 2002;82(4):475-84.

Santiago-Adame R, Medina-Torres L, Gallegos-Infante JA, Calderas F, González-Laredo RF, Rocha-Guzmán NE, Ochoa-Martínez LA, Bernad-Bernad MJ. Spray dryingmicroencapsulation of cinnamon infusions (Cinnamomum zeylanicum) with maltodextrin. LWT, 2015;64(2):571-7.

Serpen A, Gökmen V, Pellegrini N, Fogliano V. Direct measurement of the total antioxidant capacity of cereal products. J Cereal Sci, 2008;48(3):816-20.

Shamaei S, Seiiedlou SS, Aghbashlo M, Tsotsas E, Kharaghani A. Microencapsulation of walnut oil by spray drying: Effects of wall material and drying conditions on physicochemical properties of microcapsules. Innov Food Sci Emerg Technol, 2017;39:101-12.

Sharma V, Kumar HV, Rao LJM. Influence of milk and sugar on antioxidant potential of black tea. Food Res Int, 2008;41(2):124-9.

Singleton VL, Rossi JA. Colorimetry of total phenolics with phosphomolybdic-phosphotungstic acid reagent. Am J Enol Vitic, 1965;16(3):144-58.

Sousdaleff $M$, Baesso ML, Neto AM, Nogueira AC, Marcolino VA, Matioli G. Microencapsulation by freeze-drying of potassium norbixinate and curcumin with maltodextrin: Stability, solubility, and food application. J Agric Food Chem, 2013;61(4):955-65.

Von Elbe JH, Schwartz SJ. Colorants. Food Chem, 1996;3: 651-723.

Wandrey C, Bartkowiak A, Harding SE. 2010. Materials for encapsulation. In: Zuidam NJ, Nedovic V, eds. Encapsulation technologies for active food ingredients and food processing. New York: Springer, pp. 31-100.

Wang HY, Qian H, Yao WE. Melanoidins produced by the Maillard reaction: Reaction: structure and biological activity. Food Chem, 2011;128(3):573-84.

Žilić S, Akıllıoğlu HG, Serpen A, Perić V, Gökmen V. Comparisons of phenolic compounds, isoflavones, antioxidant capacity and oxidative enzymes in yellow and black soybeans seed coat and dehulled bean. Eur Food Res Technol, 2013;237(3):409-18.

Žilić S, Kocadağlı T, Vančetović J, Gökmen V. Effects of baking conditions and dough formulations on phenolic compound stability, antioxidant capacity and color of cookies made from anthocyanin-rich corn flour. LWT-Food Sci Technol, 2016;65:597-603. 
Copyright of Journal of Microencapsulation is the property of Taylor \& Francis Ltd and its content may not be copied or emailed to multiple sites or posted to a listserv without the copyright holder's express written permission. However, users may print, download, or email articles for individual use. 